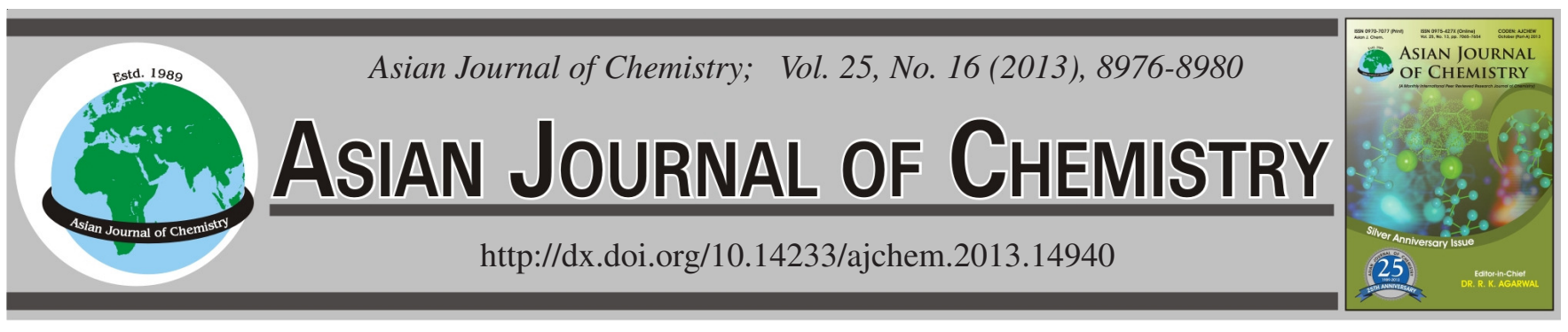

\title{
Characterization and Identification of Major Constituents in Baihe Zhimu Decoction by HPLC-MS
}

\author{
Weixin Jiang ${ }^{1}$, Zhiyu Liu ${ }^{1,2}$, Bin Wu ${ }^{2, *}$ and ChengGang Huang ${ }^{2, *}$
}

${ }^{1}$ Harbin University of Commerce, Harbin 150076, P.R. China

${ }^{2}$ Shanghai Institute of Materia Medica, Chinese Academy of Sciences, Shanghai 201203, P.R. China

*Corresponding author: E-mail: iyoo5217@163.com; cghsimm@126.com

(Received: 8 December 2012;

Accepted: 13 September 2013)

AJC-14095

\begin{abstract}
Baihe Zhimu decoction is a widely used traditional Chinese medicine recipe which has been proved effective in treating multitudinous diseases. In this paper, by comparing the retention times and $\mathrm{MS}^{\mathrm{n}}$ data with those obtained from reference substance and the published data, a total of 39 constituents including xanthones, phenolic glycosides and saponins were detected in Baihe Zhimu decoction. Therefore, this simple and specific HPLC-MS ${ }^{\mathrm{n}}$ method has been developed and applied for the primary investigation of the chemical constituents of this recipe. Besides, the data obtained in this study may be helpful for further pharmacokinetic and metabolic studies of Baihe Zhimu decoction.
\end{abstract}

Key Words: Baihe Zhimu decoction, Traditional Chinese medicine recipe, HPLC-MS ${ }^{\mathrm{n}}$

ᄂ - - - - - - - - - - - - - - - - - - - - - - - -

\section{INTRODUCTION}

A traditional Chinese medicine recipe of Baihe Zhimu decoction (BZD) was taken from the Synopsis of Prescriptions of the Golden Chamber (Jinkui Yaolue) by the Chinese therapist Zhang Zhongjing. Baihe Zhimu decoction has been widely used for lily disease, which is related to depression in modern iatrology. The ancient prescription is composed of Anemarrhena asphodeloides (Liliaceae) and Lilium brownii var. viridulum (Liliaceae). As a traditional Chinese medicine formula, Baihe Zhimu decoction is widely used to clear heat and nourish $\operatorname{yin}^{1}$. Modern pharmacological research has indicated that Baihe Zhimu decoction is effective in treating asthma $^{2}$, Alzheimer's disease ${ }^{3}$, memory decay ${ }^{4,5}$, diabetes ${ }^{6}$, cancer $^{7,8}$ and depression ${ }^{9}$. Various analytical techniques currently have been used for identification of crude extracts of Anemarrhena asphodeloides and Lilium brownii var. viridulum, but only a few researches are related to the constituents in Baihe Zhimu decoction ${ }^{10}$.

In this work, 39 constituents including 5 xanthones, 5 phenolic glycosides and 29 saponins were characterized and identified in Baihe Zhimu decoction by HPLC-MS ${ }^{\mathrm{n}}$. This approach takes the advantage in sensitivity and specificity. In addition, abundant structural information of original constituents from Baihe Zhimu decoction can be acquired by $\mathrm{MS}^{\mathrm{n}}$ techniques, which might be helpful for further pharmacokinetic and metabolic studies of Baihe Zhimu decoction.

EXPERIMENTAL

Mangiferin, neomangiferin, timosaponin AII, timosaponin AIII, timosaponin BII, timosaponin BIII and anemarrhenasaponin I were isolated from A. asphodeloides in our laboratory. Their structures were identified by NMR data and their purities were higher than $95 \%$ determined by HPLC. HPLC-grade acetonitrile and formic acid were purchased from Dikma Company (Dikma, USA). Triple deionized water was prepared using a Milli-Q system (Millipore, Billerica, MA, USA).

A. asphodeloides (No. ZM061206) was obtained from Shanghai Yanghetang Traditional Chinese Medicine Co. Ltd. (Shanghai, China) and L. brownii var. viridulum (No. BH120207) was purchased from Shanghai Kangqiao Pharmaceutical Factory Co. Ltd. (Shanghai, China). They were all authenticated by Prof. C.G. Huang, Shanghai Institute of Materia Medica, Chinese Academy of Sciences. The voucher specimens of these two species were deposited at the Herbarium of Shanghai Institute of Materia Medica.

HPLC-ESI-MS $^{\mathrm{n}}$ analysis was performed on an Agilent series 1200 HPLC instrument coupled with an Agilent 6300 series ion trap mass spectrometer. A Speed Vacplus model vacuum drier (Savant, USA) was used to prepare the samples. HPLC separation was achieved on a reversed-phase Inertsil ODS-3 column ( $4.6 \mathrm{~mm} \times 150 \mathrm{~mm}, 5 \mu \mathrm{m}$, GL Sciences, Tokyo, Japan) connected to a Dikma EasyGuard Kit $\mathrm{C}_{18}$ guard column (4 mm $\times 2$ mm, $5 \mu \mathrm{m}$, Dikma Technologies, Beijing, China). 


\begin{tabular}{|c|c|c|c|c|}
\hline No. & Identification & $\begin{array}{c}\mathrm{t}_{\mathrm{R}} \\
(\mathrm{min})\end{array}$ & $\begin{array}{l}\text { Precursor } \\
\text { ion }(\mathrm{m} / \mathrm{z})\end{array}$ & $\begin{array}{l}\text { Data-dependent } \mathrm{MS}^{\mathrm{n}} \text { data } \\
(\mathrm{m} / \mathrm{z})\end{array}$ \\
\hline 1 & Neomangiferin & 14.8 & $583[\mathrm{M}-\mathrm{H}]$ & $\begin{array}{l}\mathrm{MS}^{2} \text { [583]: 565, 493, 463, 421, 331, 301, 259;MS }{ }^{3}[493]: 331,313,273 \text {, } \\
\text { 257; } \text { MS }^{4}[331]: 313,301,285,272,259\end{array}$ \\
\hline 2 & Mangiferin & 16.3 & $421[\mathrm{M}-\mathrm{H}]^{-}$ & $\operatorname{MS}^{2}$ [421]: 403, 331, 301, 259;MS ${ }^{3}[301]: 273,257,229 ; \mathrm{MS}^{4}[257]: 229$ \\
\hline 3 & Regaloside A & 17.7 & $399[\mathrm{M}-\mathrm{H}]^{-}$ & $\operatorname{MS}^{2}[399]: 273$ \\
\hline 4 & Regaloside D & 18.1 & $399[\mathrm{M}-\mathrm{H}]^{-}$ & $\mathrm{MS}^{2}$ [399]:273 \\
\hline 5 & Isomangiferin & 20.0 & $421[\mathrm{M}-\mathrm{H}]^{-}$ & $\operatorname{MS}^{2}[421]: 403,331,301,259 ; \mathrm{MS}^{3}[301]: 273,257,229 ; \mathrm{MS}^{4}[257]: 229$ \\
\hline 6 & Regaloside E & 21.2 & $457[\mathrm{M}-\mathrm{H}]^{-}$ & $\mathrm{MS}^{2}$ [457]: $397 ; \mathrm{MS}^{3}$ [397]: 235,295 \\
\hline 7 & Mangiferin isomer & 22.8 & $421[\mathrm{M}-\mathrm{H}]^{-}$ & $\mathrm{MS}^{2}[421]: 403,331,301,259 ; \mathrm{MS}^{3}[301]: 273,257,229 ; \mathrm{MS}^{4}[257]: 229$ \\
\hline 8 & Timosaponin E1 & 28.2 & 935[M-H] $]^{-}$ & $\mathrm{MS}^{2}$ [917]: 755,5 93; $\mathrm{MS}^{3}$ [755]: 593 \\
\hline 9 & Regaloside B & 28.3 & $441[\mathrm{M}-\mathrm{H}]^{-}$ & $\operatorname{MS}^{2}[441]: 381 ; \operatorname{MS}^{3}[381]: 279,219$ \\
\hline 10 & Timosaponin E & 28.8 & $935[\mathrm{M}-\mathrm{H}]^{-}$ & $\mathrm{MS}^{2}$ [935]: 773, 611, 449;MS ${ }^{3}$ [773]: 611,449 \\
\hline 11 & 4-Acetyl derivative of regaloside $\mathrm{D}$ & 29.1 & $441[\mathrm{M}-\mathrm{H}]^{-}$ & $\operatorname{MS}^{2}[441]: 381 ; \operatorname{MS}^{3}[381]: 279,219$ \\
\hline 12 & Timosaponin D isomer & 30.4 & $917[\mathrm{M}-\mathrm{H}]^{-}$ & $\mathrm{MS}^{2}$ [917]: 755,$593 ; \mathrm{MS}^{3}$ [755]: 593; $\mathrm{MS}^{4}[593]: 415$ \\
\hline 13 & Timosaponin $\mathrm{N}$ & 30.5 & $935[\mathrm{M}-\mathrm{H}]^{-}$ & $\operatorname{MS}^{2}$ [935]: 773, 611;MS ${ }^{3}$ [773]: 611; $\mathrm{MS}^{4}$ [611]: 449 \\
\hline 14 & Timosaponin $\mathrm{D}$ isomer & 31.9 & 917[M-H]- & $\mathrm{MS}^{2}$ [917]: 755, 593; $\mathrm{MS}^{3}$ [755]: 593; $\mathrm{MS}^{4}[593]: 415$ \\
\hline 15 & Timosaponin $\mathrm{D}$ isomer & 32.5 & $917[\mathrm{M}-\mathrm{H}]^{-}$ & $\mathrm{MS}^{2}$ [917]: 755,$593 ; \mathrm{MS}^{3}$ [755]: 593; $\mathrm{MS}^{4}$ [593]: 415 \\
\hline 16 & Timosaponin BII & 33 & $919[\mathrm{M}-\mathrm{H}]^{-}$ & $\mathrm{MS}^{2}$ [919]: 757, 595; $\mathrm{MS}^{3}$ [757]: 595, 433; $\mathrm{MS}^{4}$ [595]: 433 \\
\hline 17 & 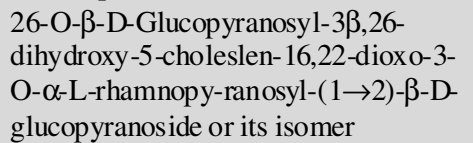 & 34.6 & $899[\mathrm{M}-\mathrm{H}]^{-}$ & $\mathrm{MS}^{2}$ [899]: 737, 575; $\mathrm{MS}^{3}$ [737]: 575 \\
\hline 18 & Timosaponin BII isomer & 34.9 & $919[\mathrm{M}-\mathrm{H}]^{-}$ & $\mathrm{MS}^{2}$ [919]: 757, 595; $\mathrm{MS}^{3}$ [757]: 595, 433; $\mathrm{MS}^{4}$ [595]: 433 \\
\hline 19 & Timosaponin D & 35.0 & 917[M-H] $]^{-}$ & $\mathrm{MS}^{2}$ [917]: 755, 593; $\mathrm{MS}^{3}$ [755]: 593; $\mathrm{MS}^{4}[593]: 415$ \\
\hline 20 & Timosaponin BII isomer & 35.3 & $919[\mathrm{M}-\mathrm{H}]^{-}$ & $\mathrm{MS}^{2}$ [919]: 757, 595; $\mathrm{MS}^{3}$ [757]: 595, 433; $\mathrm{MS}^{4}$ [595]: 433 \\
\hline 21 & Timosaponin BII isomer & 35.9 & $919[\mathrm{M}-\mathrm{H}]^{-}$ & $\mathrm{MS}^{2}$ [919]: 757, 595; $\mathrm{MS}^{3}$ [757]: 595, 433; $\mathrm{MS}^{4}$ [595]: 433 \\
\hline 22 & Timosaponin BIII isomer & 37.3 & $919[\mathrm{M}-\mathrm{H}]^{-}$ & $\mathrm{MS}^{2}$ [919]: 757, 595; $\mathrm{MS}^{3}$ [757]: 595, 433; $\mathrm{MS}^{4}[595]: 433$ \\
\hline 23 & $\begin{array}{l}\text { 26-O- } \beta \text {-D-Glucopyranosyl-3 } \beta, 26- \\
\text { dihydroxy-5-choleslen- } 16,22 \text {-dioxo-3- } \\
\text { O- } \alpha \text {-L-rhamnopy-ranosyl- }(1 \rightarrow 2)-\beta \text {-D- } \\
\text { glucopyranoside or its isomer }\end{array}$ & 37.4 & $899[\mathrm{M}-\mathrm{H}]^{-}$ & $\mathrm{MS}^{2}$ [899]: 737, 575; $\mathrm{MS}^{3}$ [737]: 575 \\
\hline 24 & Timosaponin F (C39) & 37.5 & $771[\mathrm{M}-\mathrm{H}]^{-}$ & $\mathrm{MS}^{2}$ [771]: 609; $\mathrm{MS}^{3}$ [609]: 591; \\
\hline 25 & Timosaponin BIII isomer & 37.9 & $919[\mathrm{M}-\mathrm{H}]^{-}$ & $\mathrm{MS}^{2}$ [919]: 757, 595; $\mathrm{MS}^{3}$ [757]: 595, 433; $\mathrm{MS}^{4}$ [595]: 433 \\
\hline 26 & Mangiferin norathyriol & 38 & $259[\mathrm{M}-\mathrm{H}]$ & $\mathrm{MS}^{2}$ [259]: 215 \\
\hline 27 & Timosaponin BIII isomer & 38.4 & $919[\mathrm{M}-\mathrm{H}]^{-}$ & $\mathrm{MS}^{2}$ [919]: 757, 595; $\mathrm{MS}^{3}$ [757]: 595, 433; $\mathrm{MS}^{4}$ [595]: 433 \\
\hline 28 & Timosaponin BIII & 38.6 & $901[\mathrm{M}-\mathrm{H}]^{-}$ & $\operatorname{MS}^{2}$ [901]: 739, 577; $\operatorname{MS}^{3}[739]: 577,457$ \\
\hline 29 & Timosaponin AII isomer & 39.8 & $755[\mathrm{M}-\mathrm{H}]^{-}$ & $\operatorname{MS}^{2}$ [755]: 593; $\mathrm{MS}^{3}$ [593]: 431 \\
\hline 30 & Timosaponin BII isomer & 39.9 & $919[\mathrm{M}-\mathrm{H}]^{-}$ & $\mathrm{MS}^{2}$ [919]: 757, 595; $\mathrm{MS}^{3}$ [757]: 595, 433; $\mathrm{MS}^{4}$ [595]: 433 \\
\hline 31 & Timosaponin AII isomer & 41.5 & $755[\mathrm{M}-\mathrm{H}]^{-}$ & $\mathrm{MS}^{2}$ [755]: 593; $\mathrm{MS}^{3}$ [593]: 431 \\
\hline 32 & Anemarrhenasaponin Ia & 41.7 & $771[\mathrm{M}-\mathrm{H}]^{-}$ & $\mathrm{MS}^{2}$ [771]: 609; $\mathrm{MS}^{3}$ [609]: 591; \\
\hline 33 & Anemarrhenasaponin I & 43.5 & $757[\mathrm{M}-\mathrm{H}]^{-}$ & $\operatorname{MS}^{2}$ [757]: $595 ; \mathrm{MS}^{3}$ [595]: $577,465,433$ \\
\hline 34 & Timosaponin AII isomer & 46.0 & $755[\mathrm{M}-\mathrm{H}]^{-}$ & $\mathrm{MS}^{2}$ [755]: 593; $\mathrm{MS}^{3}$ [593]: 431 \\
\hline 35 & Hydroxyl deacylbrownioside & 47.6 & $753[\mathrm{M}-\mathrm{H}]^{-}$ & $\mathrm{MS}^{2}$ [753]: 591;MS ${ }^{3}$ [591]: 573, 429, 411 \\
\hline 36 & Timosaponin AII & 48.9 & $755[\mathrm{M}-\mathrm{H}]^{-}$ & $\operatorname{MS}^{2}$ [755]: 593; $\mathrm{MS}^{3}$ [593]: 431 \\
\hline 37 & Timosaponin AIV & 52.2 & $739[\mathrm{M}-\mathrm{H}]^{-}$ & $\mathrm{MS}^{2}$ [739]: 577; $\mathrm{MS}^{2}$ [577]: 457 \\
\hline 38 & Timosaponin AIII isomer & 54.7 & $739[\mathrm{M}-\mathrm{H}]^{-}$ & $\mathrm{MS}^{2}$ [739]: 577; $\mathrm{MS}^{2}$ [577]: 457 \\
\hline 39 & Timosaponin AIII & 55.1 & $739[\mathrm{M}-\mathrm{H}]^{-}$ & $\mathrm{MS}^{2}$ [739]: 577; $\mathrm{MS}^{2}$ [577]: 457 \\
\hline
\end{tabular}

$\mathrm{MS}^{\mathrm{n}}$ analyses were conducted in negative ion mode and operating parameters were optimized as follows: collision gas, ultra high-purity helium; nebulizing gas, high-purity nitrogen; capillary voltage, $3.5 \mathrm{kV}$; end plate offset, $500 \mathrm{~V}$; nebulizer, 30 psi.; drying gas flow rate, $10 \mathrm{~L} / \mathrm{min}$; drying gas temperature, $300{ }^{\circ} \mathrm{C}$. For full-scan MS analysis, spectra were recorded in the range of 100-1500 Da.

The mobile phase was composed of acetonitrile (A) and $0.1 \%$ formic acid (B) delivered at a flow rate of $0.5 \mathrm{~mL} / \mathrm{min}$. A gradient program was used as follows: $5-10 \%$ A at 0-8 min; $10-20 \% \mathrm{~A}$ at $8-10 \mathrm{~min} ; 20 \% \mathrm{~A}$ at $10-20 \mathrm{~min} ; 20-55 \% \mathrm{~A}$ at 20-50 min and 55-100\% A at 50-70 min. At the end of the run, $100 \%$ acetonitrile was allowed to flush the column for $5 \mathrm{~min}$ and an additional $10 \mathrm{~min}$ of post-run time was set to allow equilibration of the column with the starting eluant. The system was then reconfigured to initial conditions within $30 \mathrm{~s}$ and the column was reconditioned for $4.5 \mathrm{~min}$. The column temperature was maintained at $25^{\circ} \mathrm{C}$ and the sample injection volume was $10 \mu \mathrm{L}$.

Decoction preparation: A. asphodeloides (200 g) and L. brownii var. viridulum (100 g) were immersed in $3 \mathrm{~L}$ (10 times their total weight) of deionized water for $0.5 \mathrm{~h}$. The mixture was boiled for $2 \mathrm{~h}$ and then filtered. The decoction preparation was repeated twice. The two extracts were merged and evaporated to $100 \mathrm{~mL}$ under reduced pressure at $65^{\circ} \mathrm{C}$ with a rotary evaporator. The solution was obtained at $0.3 \mathrm{~g} / \mathrm{mL}$ of Baihe Zhimu decoction and filtered through a $0.45 \mu \mathrm{m}$ membrane for LC/MS analysis. 


\section{RESULTS AND DISCUSSION}

Mass spectrometry analysis of reference compounds: It was valuable for identification of the components to realize the retention time and MS spectral data of the reference compounds. These data provided a scientific basis for identification of other compounds in Baihe Zhimu decoction. Typical $\mathrm{MS}^{\mathrm{n}}$ spectra of seven reference compounds studied in the experiment is shown in Fig. 1 (Table-1).

In the negative ion mode, high abundance of quasimolecular ion $[\mathrm{M}-\mathrm{H}]^{-}$at $\mathrm{m} / \mathrm{z} 421$ was firstly exhibited by peak 2 in reference substances and it produced three characteristic product ions at $\mathrm{m} / \mathrm{z} 403\left(\left[\mathrm{M}-\mathrm{H}-\mathrm{H}_{2} \mathrm{O}\right]^{-}\right), \mathrm{m} / \mathrm{z} 331$ ([M-H-90] $\left.]^{-}\right)$ and $m / z 301$ ([M-H-120] $]^{-}$). S2 was unambiguously identified as mangiferin. According to the literature ${ }^{11-13}$, the proposed fragmentation pathway for $\mathbf{S} \mathbf{2}$ is shown in Fig. 2(a).

S1 existed in the extracted ion chromatogram (EIC) of $\mathrm{m} / \mathrm{z} 583$ showed an increase of $162 \mathrm{Da}$ in molecular weight than that of mangiferin. Moreover, their product ion at $\mathrm{m} / \mathrm{z}$ 421 via loss of galactose (Glc) in the $\mathrm{MS}^{2}$ spectral underwent similar sequential fragmentation with the parent ion of mangiferin. Thus S1 was ascertained to be neomangiferin. The information above was important for identification and characterization of other xanthones.

Negative ESI analysis of $\mathbf{S 3}$ gave the $[\mathbf{M}-\mathrm{H}]^{-}$ion at $\mathrm{m} / \mathrm{z}$ 919. The $\mathrm{MS}^{2}$ experiment of the $\mathrm{m} / \mathrm{z}, 919$ ion yielded two prominent ions at $m / z 757$ and 595 through neutral loss of Glc (162 $\mathrm{Da})$ and an additional Gal (324 Da), respectively. The ion at $\mathrm{m} / z 757$ was subjected to $\mathrm{MS}^{3}$ analysis to yield an ion at $\mathrm{m} / \mathrm{z}$ 595 by loss of Gal (162 Da). Then $\mathrm{MS}^{4}$ spectra of $\mathrm{m} / z 595$ resulted in the ion of $\mathrm{m} / \mathrm{z}, 433$ via loss of Glc (162 Da). Based on the above data, $\mathbf{S 3}$ was confirmed as timosaponin BII. According to the literature ${ }^{14-16}$, the proposed fragmentation pathway for S3 is shown in Fig. 2(b). Uniformly, S4, S5, S6 and $\mathbf{S 7}$ were unambiguously identified as timosaponin BIII, anemarrhenasaponin I, timosaponin AII and timosaponin AIII.
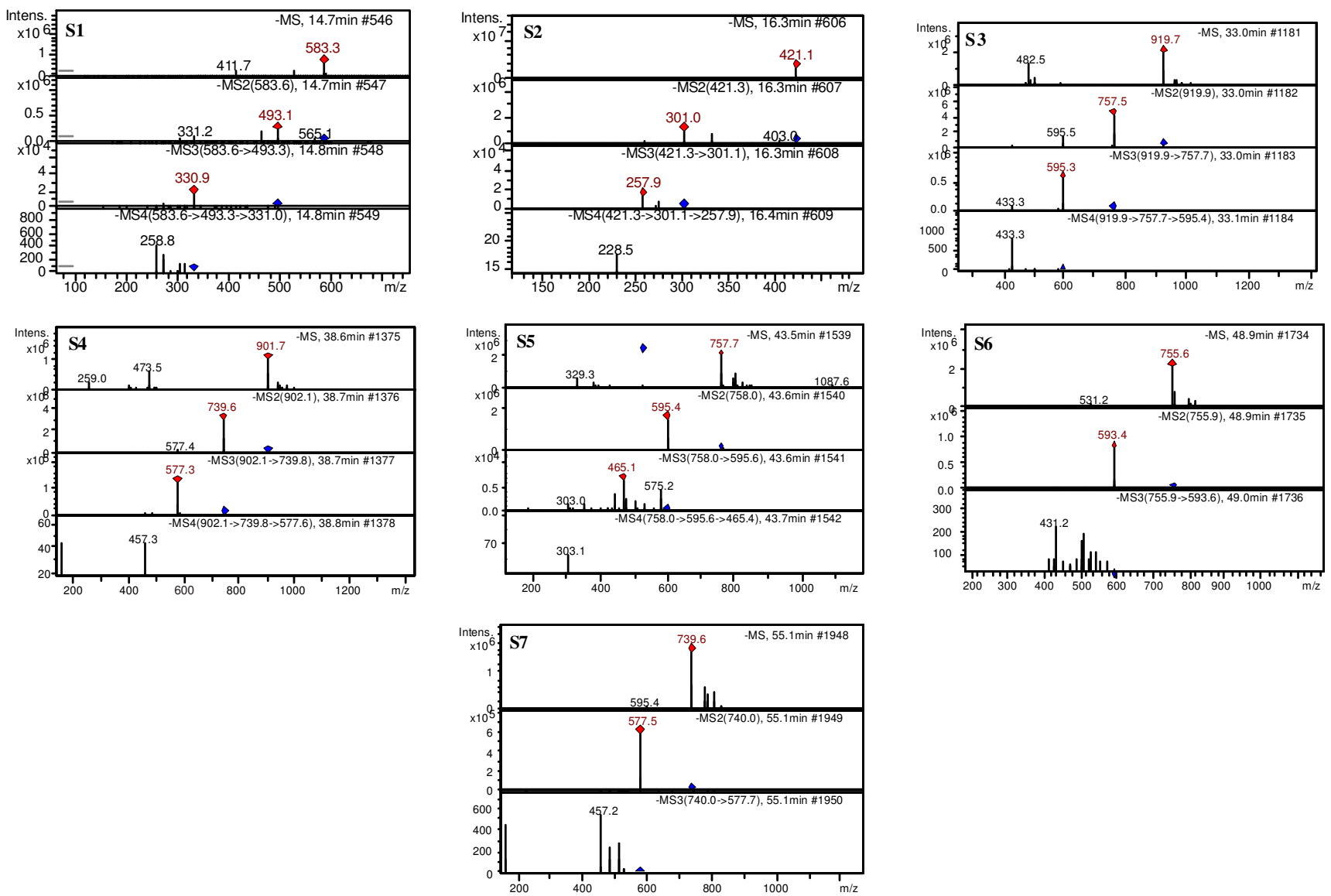

Fig. 1. ESI-MS and $\mathbf{M S}^{\mathrm{n}}$ spectra for S1-S7 in negative-ion mode

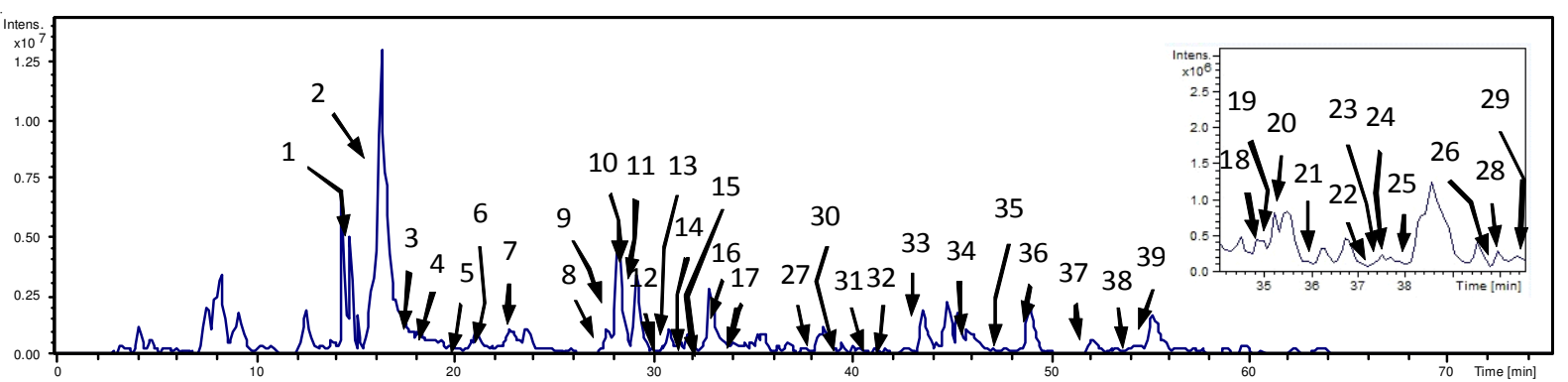

Fig. 2. Total ion chromatograms (TICs) in negative ion mode of Baihe Zhimu decoction extract 
In conclusion, the common fragmentation behavoiur of timosaponins were the successive or simultaneous losses of sugar units substituted at O-C (3), O-C (26) in the negative MS experiments. The aglycone ions with one sugar units at $\mathrm{m} / \mathrm{z} 595$ or 577 could be observed usually. The objective laws of these fragmentations discussed above were effectively used for characterization and identification of other steroid saponins in Baihe Zhimu decoction.

Characterization of the original drugs in Baihe Zhimu decoction: The original constituents in Baihe Zhimu decoction were characterized by HPLC-ESI-MS ${ }^{\mathrm{n}}$. TICs of them are presented in Fig. 3. Based on the direct comparison with chromatograms of Baihe Zhimu decoction, a total of 39 compounds were identified from Baihe Zhimu decoction and their structures are shown in Fig. 3.

Characterization of xanthones: Based on its retention behavoiur and MS spectrum obtained on-line, compound 1 was characterized as $\mathbf{S 1}$ by comparing it with the reference compound, so it was confirmed as neomangiferin.

By comparing the retention time, molecular weight and fragment ions with that of standard $\mathbf{S 2}$, compound $\mathbf{2}$ was confirmed as mangiferin. Compounds $\mathbf{5}$ and $\mathbf{7}$ underwent similar sequential fragmentation with the parent ion of mangiferin. According to the literature ${ }^{10}$, compound 5 was tentatively identified as isomangiferin and compound 7 was the isomer of mangiferin. Likewise, compound $\mathbf{2 6}$ might be mangiferin norathyriol.

Characterization of phenolic glycosides: The pseudomolecular ions of compounds 3 and $\mathbf{4}$ were $\mathrm{m} / \mathrm{z}$ 399. Ion at $\mathrm{m} / \mathrm{z} 237$ was attributed to the loss of a glucose residue. According to the polarity and the literature ${ }^{11}$, compounds $\mathbf{3}$ and $\mathbf{4}$ were tentatively identified as regaloside $\mathrm{A}$ and regaloside $\mathrm{D}$, orderly. Likewise, compound $\mathbf{6}$ could be regaloside E.<smiles>[R4]c1cc2c(=O)c3c(O)c([R4])c(O)c([R3])c3oc2cc1O</smiles>

$1 \mathrm{R}_{1}=\mathrm{H}, \mathrm{R}_{2}=\mathrm{glc}, \mathrm{R}_{3}=\mathrm{glc}$ $2 \mathbf{R}_{1}=\mathbf{H}, \mathbf{R}_{2}=$ glc, $\mathbf{R}_{3}=\mathrm{OH}$ $5 \mathrm{R}_{1}=\mathrm{glc}, \mathrm{R}_{2}=\mathrm{H}, \mathbf{R}_{3}=\mathrm{OH}$ $26 \mathrm{R}_{1}=\mathrm{H}, \mathbf{R}_{2}=\mathrm{H}, \mathbf{R}_{3}=\mathrm{OH}$<smiles>O=C(/C=C/c1ccc(O)cc1)OCC(O)COC1OC2(CO)OC(O)C1C(O)C2O</smiles><smiles>[R4]CC(COC(=O)/C=C/c1ccc(O)c(Br)c1)O[C@@H]1O[C@H](CO)[C@@H](O)[C@H](O)[C@H]1O</smiles>

$4 \mathrm{R}_{1}=\mathrm{H}, \mathrm{R}_{2}=\mathrm{OH}$ $6 R_{1}=O H, R_{2}=A c$
$9 R_{1}=H, R_{2}=A c$

Fig. 3. Chemical structures of some identified compounds in Baihe Zhimu decoction
Compounds 9 and $\mathbf{1 1}$ showed the $[\mathrm{M}-\mathrm{H}]^{-}$at $\mathrm{m} / \mathrm{z}, 441$ in full scan mass spectra and their corresponding $\mathrm{MS}^{2}$ spectrum showed dominant ion at $m / z 279$ ([M-H-Glc $\left.]^{-}\right)$. In literature $^{11}$, compound 9 was identified as regaloside B, while compound $\mathbf{1 1}$ was identified as 4-acety derivative of regaloside D.

Characterization of saponins: By comparison with the standard and referring to the literature ${ }^{14-16}$, compound $\mathbf{1 6}$ was unambiguously identified as timosaponin BII which has been described to possess various pharmacological activities ${ }^{3}$. Compounds 18, 20, 21 and 30 were tentatively identified as its isomers. Compounds 22, 25 and 27 displayed similar characteristic fragment ions with $\mathbf{S 4}$, according to the retention time and literature ${ }^{14}$, compound $\mathbf{2 8}$ could be unambiguously identified as timosaponin BIII, while other five compounds might be its isomers. Similarly, compound $\mathbf{3 3}$ was confirmed as anemarrhenasaponin I. In addition, compounds $\mathbf{3 6}$ and $\mathbf{3 9}$ were unambiguously identified as timosaponin AII and timosaponin AIII by comparison with the standards and referring to the literature $^{14,17}$. Compounds 29, $\mathbf{3 1}$ and $\mathbf{3 4}$ were proposed to be the isomers of timosaponin AII, compounds $\mathbf{3 7}$ and $\mathbf{3 8}$ were deduced to be the isomers of timosaponin AIII.

Three compounds coexisted in the extracted ion chromatogram (EIC) of $\mathrm{m} / \mathrm{z}, 935$ showed different fragment ions in the MS spectra. Compounds $\mathbf{8 , 1 0}$ and $\mathbf{1 3}$ gave major product ions on $\mathrm{MS}^{2}$ were $[\mathrm{M}-\mathrm{H}-18]^{-}\left(\mathrm{m} / \mathrm{z}\right.$ 917) and [M-H-18-162] ${ }^{-}$ $(\mathrm{m} / \mathrm{z}, 755)$. Its $\mathrm{MS}^{3}$ fragmentation was predominated by the successive elimination of galactose residue from [M-H-18$162]^{-}(\mathrm{m} / \mathrm{z}, 755)$ to give ion at $\mathrm{m} / \mathrm{z}$ 593. Moreover, compounds 10 and 13 successively eliminated a series of hexoses. According to the polarity and the literature ${ }^{10}$, it is concluded that compounds 8, 10 and $\mathbf{1 3}$ tentatively identified as timosaponin $\mathrm{E}$, timosaponin $\mathrm{E}$ and timosaponin $\mathrm{N}$, orderly.
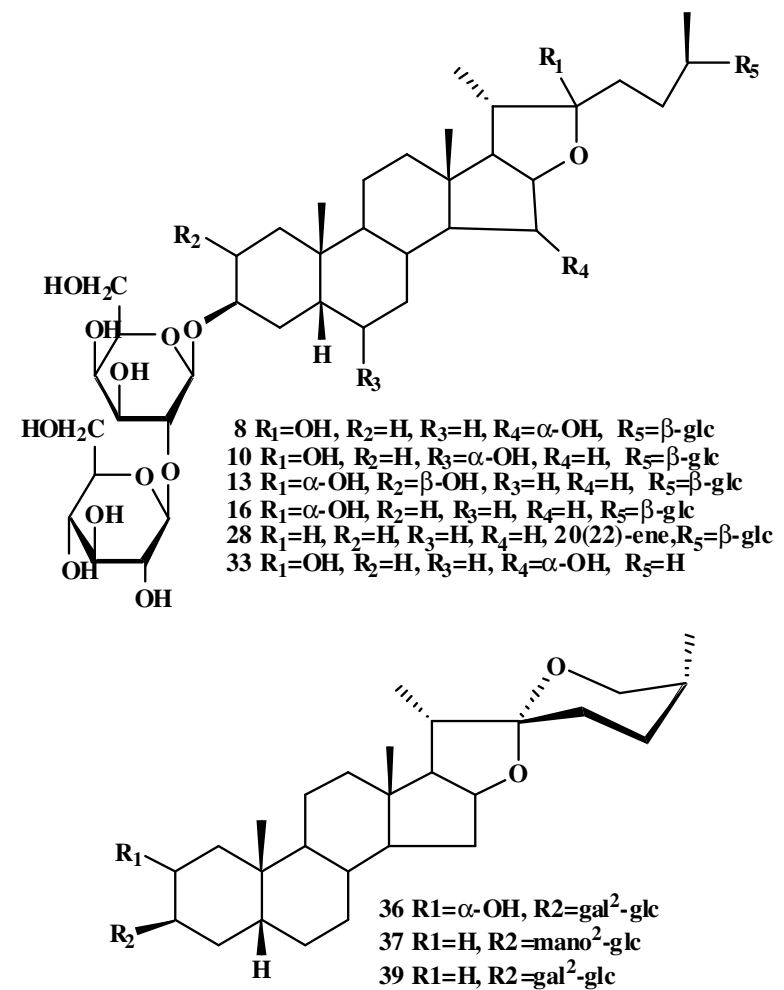
Compounds 12, 14, 15 and 19 showed $[\mathrm{M}-\mathrm{H}]^{-}$ion at $\mathrm{m} / \mathrm{z}$ 917. The fragment ion at $m / z, 755$ on $\mathrm{MS}^{2}$ may be formed by the loss of a glucose residue. The product ion at $\mathrm{m} / z$. 593 on $\mathrm{MS}^{3}$ corresponded to successive loss of a galactose residue, while the product ion at $\mathrm{m} / \mathrm{z} 451$ on MS4 corresponded to successive loss of a galactose residue and $\mathrm{a}_{2} \mathrm{O}$ molecule. On the basis of previous findings ${ }^{10}$, the retention time of timosaponin D was between timosaponin BII and timosaponin BIII, compound 19 proposed to be timosaponin D. And compounds 12, 14 and 15 were tentatively identified as its isomers.

Two peaks with different retention times appeared in the extracted ion chromatogram (EIC) of $m / z$ 771. All successive MS/MS fragmentations showed decrease of 162 and $18 \mathrm{Da}$ in molecular weight ascribed to loss of a hexose and $\mathrm{H}_{2} \mathrm{O}$ unit. According to the polarity and the literature ${ }^{10}$, we concluded that compounds $\mathbf{2 4}$ and $\mathbf{3 2}$ could be timosaponin F and anemarrhenasaponin Ia.

Compound 35 had a $[\mathrm{M}-\mathrm{H}]^{-}$at $\mathrm{m} / \mathrm{z}, 753$ and the $\mathrm{MS}^{2}$ spectrum had a fragment at $m / z 591$ (M-162 Da, loss of a Glc) and a fragment at $m / z 573(\mathrm{M}-162 \mathrm{Da}-18 \mathrm{Da}$, loss of a Glc and $\mathrm{a}_{2} \mathrm{O}$ ). The fragments at $\mathrm{m} / \mathrm{z}, 591$ and 573 further lost 162 $\mathrm{Da}$ and produced fragments at 429 and 411 on $\mathrm{MS}^{3}$, respectively. This suggested the existences of hydroxyl and hexoses. This compound had not previously been reported form natural sources or synthesis from Lilium brownii var. viridulum. In literature $^{11}$, it was tentatively identified as hydroxyl deacylbrownioside, which might be oxidized from deacylbrownioside during boiling.

Compounds $\mathbf{1 7}$ and $\mathbf{2 3}$ had the [M-H] at $m / z 899$ that fragmented on $\mathrm{MS}^{2}$ to produce ions at $m / z 737$ (M-146-16 Da, loss of a rha and a O). The fragment at $m / z, 737$ further lost $162 \mathrm{Da}$ and produced fragment at 575 on $\mathrm{MS}^{3}$. Thus, compounds 17 and 23 might be 26-O- $\beta$-D-glucopyranosyl-3 $\beta, 26-$ dihydroxy-5-choleslen-16,22-dioxo-3-O- $\alpha$-L-rhamnopyranosyl- $(1 \rightarrow 2)-\beta$-D-glucopyranoside and its isomer.

\section{Conclusion}

In this study, a HPLC-ESI-MS ${ }^{\mathrm{n}}$ method was developed to analyze the constituents of Baihe Zhimu decoction. As a result, a total of 39 compounds were identified or tentatively characterized from Baihe Zhimu decoction extract. The fragmentation patterns of these reference substances, which could be classified into three types including, xanthones phenolic glycosides, observed in an HPLC-ESI-MS ${ }^{\mathrm{n}}$ were analyzed to further identify these structures. In brief, the major fragmentations of phenolic glycosides and saponins corresponded to the losses of branched glycoside chains. The major fragmentations of xanthones norathyriol corresponded to the losses of small molecules such as Me and COO. Moreover, losses of 120 and $90 \mathrm{Da}$ were observed, corresponding to cross-ring cleavages in the sugar moiety, which is the major characteristic of C-C linked $\beta$-Dglucopyranosides. Owing to the structural complexity of constituents in Baihe Zhimu decoction, the origins and structures of some compounds could not be definitely elucidated under the current analytical conditions. But the similarities of constituents detected in Baihe Zhimu decoction will be very helpful in revealing the therapeutic basis of Baihe Zhimu decoction.

\section{ACKNOWLEDGEMENTS}

The authors thank the National Science \& Technology Major Project "Key New Drug Creation and Manufacturing Program", China (No. 2012ZX09301001-001) and the Key and General Programs of National Natural Science Foundation of China (No. 81274055) for financial support of this work.

\section{REFERENCES}

1. H.F. Wang, H.Q. Xu and M.M. Chen, Zhonghua Zhongyiyao Zazhi, 25, 531 (2010).

2 X.L. Ma, Y.R. An and T. Qiu, Progr. Modern Biomed., 12, 1423 (2012).

3 T.J. Li, Y. Qiu, P.Y. Yang, Y.C. Rui and W.S. Chen, Neurosci. Lett., 421, 147 (2007).

4 B. Lee, K. Jung and D.H. Kim, Pharmacol. Biochem. Behav., 93, 121 (2009).

5 G.L. Pardo, N. Maurmann, G. Kellermann, C. Farias, G. Schwartsmann, R. Delgado and R. Roesler, Eur. J. Pharmacol., 635, 124 (2010).

6 X.P. Ye, C.Q. Song, P. Yuan and R.G. Mao, Chin. J. Nat. Med., 8, 349 (2010).

7 F.W. King, S. Fong, C. Griffin, M. Shoemaker, R. Staub, Y.L. Zhang, I. Cohen and E. Shtivelman, Plos One, 4, 1 (2009).

8 Y.J. Kang, H.J. Chung, J.W. Nam, H.J. Park, E.K. Seo, Y.S. Kim, D. Lee and S.K. Lee, J. Nat. Med., 74, 701 (2011).

9 S.Q. Zheng, Theoretical and Experimental Studies on the Anti-depression Effect of Baihe-Zhimu Decoction, Shanghai, The Second Military Medical University, College of Pharmacy (2007).

10 K.R. Wang, Z.Y. Zhu and L. Yang, Rapid Commun. Mass Sp., 25, 9 (2011).

11 K.M. Qin, H. Cai and X. Liu, Pharmacogn. Mag., 7, 177 (2011).

12 H. Wang, G. Ye and C.H. Ma, J. Pharm. Biomed. Anal., 45, 793 (2007).

13 H.H. Liu, K. Wang, Y.H. Tang, Z.L. Sun, L.H. Jian, Z.X. Li, B. Wu and C.G. Huang, J. Pharm. Biomed. Anal., 55, 1075 (2011).

14 C.H. Ma, L.X. Wang and Y.H. Tang, Biomed. Chromatogr, 22, 1066 (2008).

15 F. Cai, W. Xu, H. Wei, L.N. Sun, S.H. Gao, Q. Yang, J. Feng, F. Zhang and W.S. Chen, J. Chromatogr. B, 878, 1845 (2010).

16 C.H. Ma, M.S. Fan, Y.H. Tang, Z.X. Li, Z.L. Sun, G. Ye and C.G. Huang, Biomed. Chromatogr., 22, 835 (2008).

17 H.Y. Mei, Y.T. Wang, S.C.W. Sze, K.W. Tsang, H.K. Wong, Q. Liu, L.D. Zhong and Y. Tong, Biomed. Chromatogr., 24, 479 (2010). 